\title{
The influence of acetyl phosphate on DspA signalling in the Cyanobacterium Synechocystis sp. PCC6803 S Shawn Morrison ${ }^{1}$, Conrad W Mullineaux ${ }^{2,3}$ and Mark K Ashby*1,3
}

\begin{abstract}
Address: ${ }^{1}$ Department of Basic Medical Sciences, Biochemistry Section, the University of the West Indies, Mona Campus, Kingston 7, Jamaica, ${ }^{2}$ Department of Biology, University College London, Darwin Building, Gower Street, London WC1E 6BT, UK and ${ }^{3}$ School of Biological and Chemical Sciences, Queen Mary, University of London, Mile End Road, London E1 4NS, UK

Email: S Shawn Morrison - sshawn58@hotmail.com; Conrad W Mullineaux - c.mullineaux@qmul.ac.uk; Mark K Ashby* - m.ashby@qmul.ac.uk

* Corresponding author
\end{abstract}

Published: 02 August 2005

BMC Microbiology 2005, 5:47 doi:10.1 |86/147|-2/80-5-47
Received: 22 March 2005

Accepted: 02 August 2005

This article is available from: http://www.biomedcentral.com/I47/-2/80/5/47

(C) 2005 Morrison et al; licensee BioMed Central Ltd.

This is an Open Access article distributed under the terms of the Creative Commons Attribution License (http://creativecommons.org/licenses/by/2.0), which permits unrestricted use, distribution, and reproduction in any medium, provided the original work is properly cited.

\begin{abstract}
Background: The dspA (hik33) gene, coding for a putative sensory histidine kinase, is conserved in plastids (ycf26) and cyanobacteria. It has been linked with a number of different stress responses in cyanobacteria.

Results: We constructed an insertional mutant of dspA (ycf26) in Synechocystis 6803. We found little phenotypic effect during nitrogen starvation. However, when the mutation was combined with deletion of the pta gene coding for phosphotransacetylase, a more significant phenotype was observed. Under nitrogen starvation, the pta/dspA double mutant degrades its phycobilisomes less than the wild type and still has about half of its chlorophyll-protein complexes.
\end{abstract}

Conclusion: Our data indicates that acetyl-phosphate-dependent phosphorylation of response regulator(s) overlaps with DspA-dependent signalling of the degradation of chlorophyll-protein complexes (and to a lesser extent phycobilisomes) in Synechocystis 6803.

\section{Background}

The assembly, composition and maintenance of photosynthetic pigment-protein complexes are regulated by many different factors including light quality, light intensity, temperature, water availability and nutrient status [1]. Microorganisms have diverse mechanisms for sensing and acclimating to environmental parameters. In bacteria, two-component signal transduction pathways form a major part of the signalling machinery, mediating adaptive responses to a broad range of environmental stimuli [2-4]. In response to such stimuli, a sensor kinase autophosphorylates an internal histidine residue, and then transfers the phosphate to a conserved aspartate residue on the receiver domain of its cognate response regulator.
The phosphorylation of the response regulator often leads to changes in gene transcription [5].

Response regulators are generally phosphorylated by their cognate sensor kinases, but phosphorylation can also be mediated through low molecular mass phosphate donors, such as acetyl phosphate, phosphoramidate $\left(\mathrm{NH}_{2} \mathrm{PO}_{3}\right)$ and carbamyl phosphate [6-9]. The pta gene encodes phosphotransacetylase which catalyses the production of acetyl phosphate, the activated acetate intermediate that occurs during conversion of acetyl-CoA to acetate [10]. Chamnongpol \& Groisman [11] identified acetyl phosphate as the phosphate donor for a mutant version of the response regulator PhoP $\left(\mathrm{PhoP}^{*}\right)$ and showed that inactivation of the pta gene abolished $\mathrm{PhoP}^{*}$-mediated 
transcription. Most response regulators can be phosphorylated by acetyl phosphate in vitro [8], but at physiological concentration this may not be significant depending on the $K_{m}$ for each individual response regulator for acetyl phosphate. It may be that acetyl phosphate maintains a low level of phosphorylation for most response regulators. The pta gene has been identified in Synechocystis 6803 (slr2132) and Crocosphaera watsonii by homology to other bacterial pta sequences (up to $47 \%$ sequence identity by BLASTP), however pta has not been identified in the genome sequence of the other cyanobacteria.

The gene $d s p \mathrm{~A}(y c f 26)$ codes for a putative sensory histidine kinase that is conserved in plastids and cyanobacteria. The deduced amino acid sequence of DspA contains 663 amino acids in Synechocystis sp. PCC 6803 (Synechocystis 6803). DspA has a HAMP [12] and a PAS sensor domain [13]. We have also identified a possible additional sensory domain in Ycf26, which will be discussed below. All cyanobacterial genomes sequenced to date contain an ORF encoding a Ycf26 orthologue and $y c f 26$ is also the only histidine kinase gene present in the plastid genomes of the red algae Porphyra purpurea, Gracilaria tenuistipitata and Cyanidium caldarium [14]. This suggests that it performs a key role in the regulation of the level of photosynthetic pigment-protein complexes.

The probable orthologue for Ycf26 in the cyanobacterium Synechocystis 6803 is an ORF designated sll0698 in the CyanoBase genome database http://www.kazusa.or.jp/ cyano which has also been called Hik33 [15] and DspA [16]. It was identified as a factor that confers resistance to a variety of herbicides and was suggested to be a histidine kinase involved in chemical sensing [16]. It was found to be involved in gene expression (including photosynthesis-related genes), demonstrating characteristics of a sensor that can detect a decrease in membrane fluidity, and is involved in the perception and transduction of salt stress and low temperature signals in Synechocystis 6803 $[15,17,18]$. Deletion of this open reading frame leads to global changes in gene expression $[19,20]$ and in addition a potential link has been identified between Hik33 and Rre31 (RpaA). In another cyanobacterium, Synechococcus sp. PCC7942 (Synechococcus 7942), the probable orthologue for Ycf26 was shown to regulate phycobilisome degradation during nutrient starvation and in high light. The gene was therefore designated nbls (non-bleaching mutant sensor) [21]. DspA is also important for the survival of Synechocystis 6803 when grown in high-light [22]. One possible cognate response regulator (NblR) has been identified in Synechococcus 7942 for NblS, however, no orthologue for NblR has been identified in Synechocystis 6803 (MK Ashby \& J Houmard, unpublished) and it is likely that NblS also interacts with other response regulators [21]. NblS has been proposed to integrate redox and light signals and may influence other signalling pathways involved in acclimation responses [21]. Thus it appears that the orthologues of DspA in other cyanobacteria have different but overlapping functions.

A role for the sll0698 gene product in controlling the degradation of the photosynthetic apparatus during nutrient stress has not yet been demonstrated in Synechocystis 6803. We have constructed an insertional deletion mutant in this ORF, which we will refer to as $d s p A$. We show that the inactivation of $d s p A$ has little phenotypic effect under nitrogen starvation, unless the mutation is combined with deletion of the pta gene. In the double mutant there is a dramatic effect on the degradation of chlorophyll-protein complexes under nitrogen starvation, which is not seen in either of the single mutants, however phycobilisomes are degraded, though not to the same level as in wild type. We conclude that acetyl phosphate masks DspA signalling under our laboratory conditions. The results indicate that the degradation of photosynthetic complexes during nutrient stress is controlled by multiple inputs, including acetyl phosphate level.

\section{Results \\ Analysis of cyanobacterial and plastid deduced Ycf26 protein sequences}

The deduced amino acid sequences for Ycf26 from 15 available cyanobacterial annotated genome sequences and the red algal species Porphyra purpurea, Gracilaria tenuistipitata and Cyanidium caldarium were analysed by Pfam and SMART. This identified a HAMP, PAS (low confidence in Cyanidium), HisKA and HATPase_c domain (Figure 1). SMART and Interpro also identified two potential transmembrane helical regions upstream of the HAMP domain (33-55 and 201-223 in 6803). The identification of transmembrane sequences by SMART is with an accuracy of $97-98 \%$ [23]. Because the 145 amino acid region that is flanked by the two transmembrane regions is highly conserved in all 15 cyanobacterial sequences and Porphyra (see additional figure online and Prodom Family

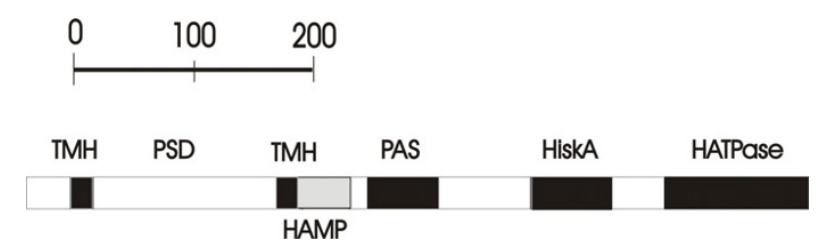

Figure I

Cartoon of the domain structure of Ycf26 (NbIS, DspA). HAMP - histidine kinase and methyl-accepting proteins; HisKA and HATpase - catalytic domains of histidine kinase; PAS - period protein, aryl hydrocarbon receptor nuclear translocator protein and single-minded protein; PSD - Putative sensor domain; TMH - Trans membrane helix; 
Table I: Bacterial strains and plasmids used

\begin{tabular}{|c|c|c|}
\hline Strain & Description & Reference/Source \\
\hline Synechocystis 6803 & Glucose-tolerant 'wild-type' strain & [35] \\
\hline pta & $\begin{array}{l}\text { ORF slr2 } 132 \text { inactivated by insertion of } \mathrm{Em}^{\mathrm{R}} \text { gene into Pstl site at position } I, 25 I, 3 \mid 3 \text { of the genome } \\
\text { ( } 872 \text { bp into the coding seq of slr2I32). }\end{array}$ & This study \\
\hline$d s p A$ & $\begin{array}{l}\text { ORF sll0698 inactivated by insertion of } \mathrm{Km}^{\mathrm{R}} \text { gene into EcoR I site at position } 125,060 \text { of the genome } \\
\text { (I384 bp into the coding seq of sll0698). }\end{array}$ & This study \\
\hline ptadspA & ORF sll0698 inactivated in pta & This study \\
\hline pBluescriptll KS + & Multipurpose cloning vector with $\mathrm{Amp}^{\mathrm{R}}$. & Stratagene \\
\hline pBSEmEcol & Cloned $\mathrm{Em}^{\mathrm{R}}$ gene cassette. & {$[48,49]$} \\
\hline pUC4K & Cloned $\mathrm{Km}^{\mathrm{R}}$ gene cassette & Stratagene \\
\hline
\end{tabular}

Table 2: Pigment contents of Synechocystis 6803 wild-type and mutants. Data before and after nitrogen starvation for 3 days at $80 \mu$ mol $\mathrm{m}^{-2} \mathrm{~s}^{-1}$ as described in Experimental Procedures. Pigment concentrations and cell densities were estimated from absorption spectra. Values given are the means of three replicates, with standard deviations. Asterisks indicate pigment concentrations that were too low to be accurately determined. All media contained glucose.

\begin{tabular}{|c|c|c|c|c|c|c|}
\hline \multirow[t]{2}{*}{ Strain } & \multicolumn{2}{|c|}{ Chlorophyll/Cell (molecules $\left.\times 10^{6}\right)$} & \multicolumn{2}{|c|}{ Phycocyanin/Cell (molecules $\times 10^{6}$ ) } & \multicolumn{2}{|c|}{ Chlorophyll/phycocyanin } \\
\hline & +nitrate & -nitrate & +nitrate & -nitrate & +nitrate & -nitrate \\
\hline Wild-type & $13.6 \pm 2.1$ & $*$ & $5.6 \pm 1.4$ & $*$ & $2.4 \pm 0.1$ & $*$ \\
\hline pta & $12.6 \pm 0.4$ & * & $4.6 \pm 1.5$ & * & $2.7 \pm 0.1$ & * \\
\hline dspA & $13.8 \pm 0.1$ & $*$ & $5.9 \pm 0.5$ & $*$ & $2.4 \pm 0.1$ & $*$ \\
\hline ptaldspA & $15.8 \pm 0.9$ & $7.8 \pm 0.5$ & $5.9 \pm 0.5$ & $1.0 \pm 0.2$ & $2.7 \pm 0.2$ & $7.8 \pm 2.3$ \\
\hline
\end{tabular}

PD339187 [24]) and it is adjacent and upstream of a HAMP domain (which is known to in most cases be actively involved in transmission of signals from a periplasmic signalling domain to the cytoplasmic portion of the protein $[12,25,26])$, we think it probably functions as a periplasmic sensor. We have not been able to detect homologous sequences in any other protein sequence, suggesting that it is unique to Ycf26 (DspA/NblS). The PAS sensor domain may bind a redox sensitive cofactor [13] that could potentially report on the metabolic state of the cell. Phylogenetic analysis (Ashby, MK and Houmard, J unpublished) and ClustalW alignments of these sequences and the alignment scores indicate that all these proteins (except Cyanidium caldarium and Gracilaria tenuistipitata) are probably orthologues (see supplementary data online). This is supported by Tu et al., [19] who were able to rescue their $d s p A$ null mutant in Synechocystis 6803 with the nblS gene from Synechococcus 7942.

\section{Phenotype of the pta, dspA and pta/dspA mutants under nutrient-replete conditions}

Mutants were routinely characterised by whole cell absorption spectra, which can be used to give an estimate of the amount of chlorophyll and phycocyanin per cell [27]. Mutants were further characterised by $77 \mathrm{~K}$ fluorescence emission spectra. These spectra give an indication of changes in the PSII:PSI ratio [28].
When cells were grown under low light (white light at 10 $\mu \mathrm{mol} \mathrm{m} \mathrm{m}^{-2} \mathrm{~s}^{-1}$ ) the absorption spectra were similar, indicating little difference in the chlorophyll and phycocyanin content of the cells (data not shown). When cells were grown under higher light $\left(80 \mu \mathrm{mol} \mathrm{m} \mathrm{m}^{-2} \mathrm{~s}^{-1}\right)$, only slight differences in absorption spectra and $\mathrm{Chl} / \mathrm{PC}$ ratios were seen (Table 2). However low-temperature fluorescence spectra recorded with chlorophyll excitation revealed changes in the ratio of PSII/PSI (Figure 2). These spectra show peaks at $685 \mathrm{~nm}$ and $695 \mathrm{~nm}$ (both from PSII) and $725 \mathrm{~nm}$ (PSI) $[28,29]$. Spectra have been normalised to the PSI fluorescence emission, as their absolute amplitudes are unreliable [28]. When cells were grown at 80 $\mu \mathrm{mol} \mathrm{m} \mathrm{m}^{-2} \mathrm{~s}^{-1}$, the $d s p A$ and $p t a$ single mutants show a lower PSII/PSI ratio than the wild-type, and this difference was more pronounced in the $p t a / d s p A$ double mutant (Figure 2 ). A similar pattern was seen in cells grown at $10 \mu \mathrm{mol} \mathrm{m}-$ ${ }_{2} \mathrm{~s}^{-1}$, but the differences were less pronounced (not shown).

\section{Phenotype of the pta, dspA and pta/dspA mutants after nitrogen starvation}

An nblS mutant of Synechococcus 7942 shows a pronounced phenotype under nitrogen starvation. In the wild-type, cells gradually lose their photosynthetic pigments under these conditions. However, an nblS mutant is bleached to a much lesser extent, retaining its 


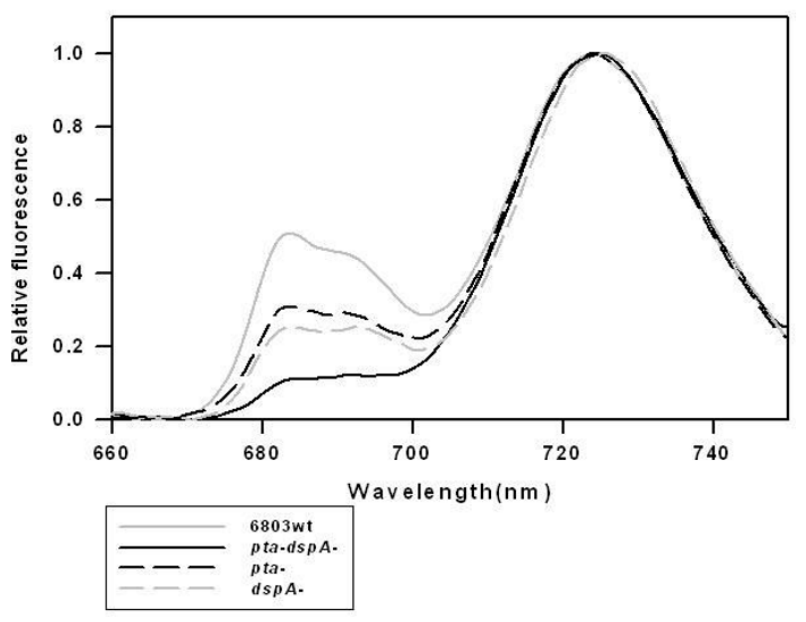

Figure 2

$77 \mathrm{~K}$ fluorescence emission spectra for cells grown under nutrient-replete conditions. Synechocystis 6803 wild-type and mutants. Excitation is at $435 \mathrm{~nm}$ (chlorophyll excitation) and spectra are normalised to the PSI fluorescence emission peak at $725 \mathrm{~nm}$. Cells grown under moderately high light $\left(80 \mu \mathrm{mol} \mathrm{m}^{-2} \mathrm{~s}^{-1}\right)$.

phycobilisomes in particular [21]. We therefore looked at the pigmentation of our Synechocystis 6803 mutants during growth in modified BG11 medium supplemented with glucose (to help maintain the viability of the cells), but containing no $\mathrm{NaNO}_{3}$.

After three days nitrogen starvation in moderate light $(80$ $\mu \mathrm{mol} \mathrm{m} \mathrm{m}^{-2} \mathrm{~s}^{-1}$ ), the wild-type and the $d s p A$ and pta single mutants were almost completely bleached (Table 2). We could detect no significant differences (less than 5\%) in the rate of bleaching during nitrogen starvation in the three strains (data not shown). By contrast, the pta/dspA double mutant retained significant levels of pigment (Table 2). Both the chlorophyll and phycocyanin per cell dropped somewhat compared to the start of the treatment, but loss of phycocyanin was much greater (Table 2 ). Thus only the pta/dspA double mutant shows a 'nonbleaching like' phenotype: Chlorophyll concentration decreases by a factor of about two and that of phycocyanin by about five. Figure 3 shows low-temperature fluorescence emission spectra for the $p t a / d s p A$ double mutant grown after 3 days nitrogen starvation. Whether with or without nitrate, it exhibits a similar spectrum meaning that the starved cells retain both PSI and PSII. The starved $p t a-/ d s p A^{-}$cells also retained significant levels of oxygen

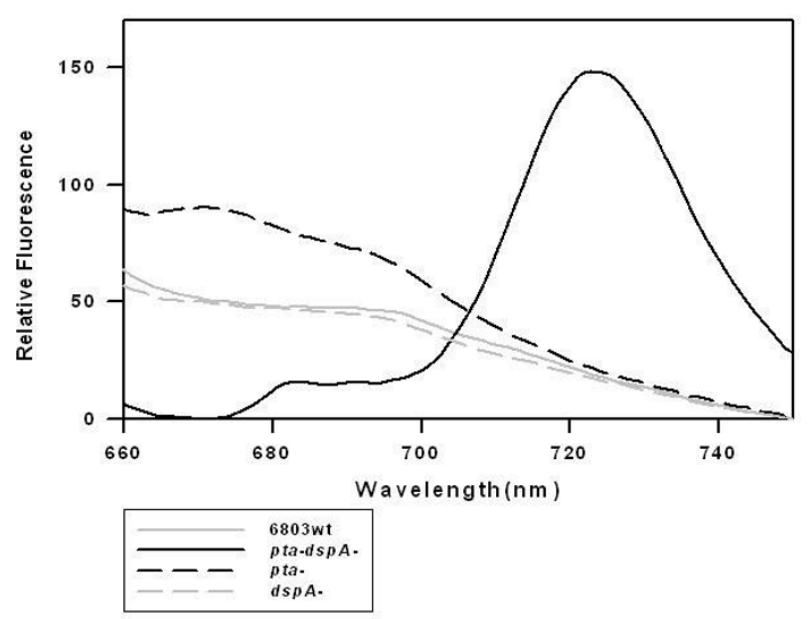

Figure 3

$77 \mathrm{~K}$ fluorescence emission spectra for cells after growth in nitrate-depleted medium. Synechocystis 6803 wild-type and mutants grown for 3 days in these conditions. Excitation is at $435 \mathrm{~nm}$.

evolution (data not shown). Thus the pta/dspA double mutant retains its photosynthetic apparatus during nitrogen starvation, in contrast to the wild-type and both single mutants, where nearly all pigment is lost.

\section{Discussion}

A potential new sensor domain in DspA/Ycf26

Ycf26 may have a periplasmic sensor domain, which could play an important role in sensing stress either directly or indirectly (Figure 1). The putative periplasmic sensor and PAS domain may combine to enable Ycf26 to sense a wide variety of stress conditions [[15,17-19,21,22] \& this work]. It remains to be determined whether DspA senses any of these signals directly or via other proteins or phosphorelays and the precise way in which these sensor domains interact. This apparent central role of Ycf26 in the regulation of gene expression in response to a number of different stresses is supported by its universal occurrence in the 15 available cyanobacterial genome sequences, particularly the 3 Prochlorococcus species which only have 4-6 histidine kinases in their genome ([30], MK Ashby \& J Houmard, unpublished).

\section{Roles of DspA and acetyl phosphate in cell signalling}

We have constructed Synechocystis 6803 mutants deficient in the pta gene coding for phosphotransacetylase and the $d s p A$ gene coding for the DspA sensory histidine kinase (otherwise known as Ycf26 or NblS), and a double mutant 


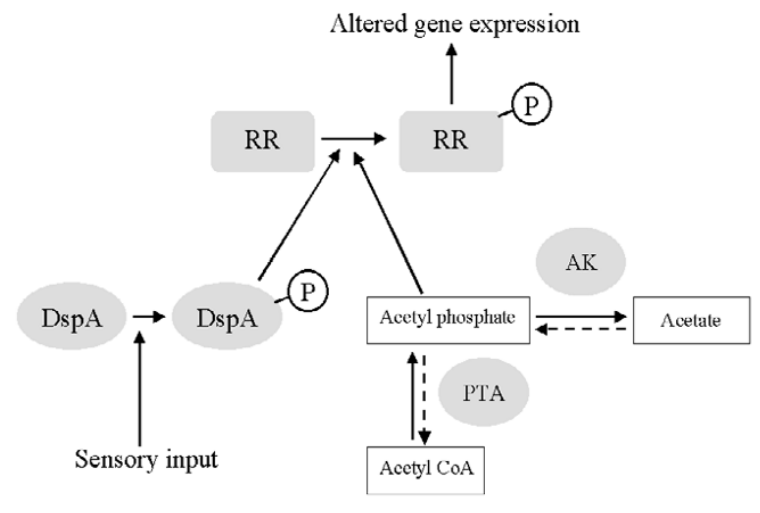

Figure 4

Simplest model that fits the data for information flow during DspA signalling. Acetyl phosphate and DspA can both act as phosphodonors to one or more response regulators. Under nitrogen starvation, phosphorylation by either acetyl phosphate or DspA alone is sufficient to saturate the response. Thus pta or $d s p A$ single mutants behave like the wild-type, and only the pta-dspA-double mutant has a distinctive phenotype. Under other conditions the steadystate phosphorylation level of the response regulators (or hybrid kinases) is not saturated either by acetyl phosphate or by DspA alone. Then pta and dspA deletions have additive effects. Both single mutants show a phenotypic change, but a stronger effect is seen in the double mutant. RR: response regulator; AK: acetate kinase; PTA: phosphotransacetylase.

deficient in both genes. We have used the mutants to examine the possible roles of DspA and acetyl phosphate in controlling cell responses to nitrogen starvation. We find strong evidence that DspA and acetyl phosphate act cooperatively as signalling inputs into pathways controlling photosystem stoichiometry under nutrient-replete conditions, and photosystem degradation during nitrogen starvation. Under nutrient-replete conditions, the $d s p A$ and pta single mutants both show a decreased PSII/ PSI ratio (Figure 2). The PSII/PSI ratio becomes even lower in the $p t a / d s p A$ double mutant, indicating additive effects of the two mutations. Since acetyl phosphate is known to act as a phosphodonor to response regulators [11], we propose that PSII/PSI ratio is influenced by gene expression controlled by one or more response regulators (or hybrid kinases) whose phosphorylation level is controlled by phosphotransfer both from DspA and from acetyl phosphate. This scheme (in its simplest form) is illustrated in Figure 4.

The effects seen under nitrogen starvation are even more striking. After 3 days' nitrogen starvation under moderate light, wild-type cells are virtually devoid of pigment, indicating almost complete loss of the phycobilisomes and the chlorophyll-protein complexes (Table 2). In this case, the $d s p A$ and pta single mutants both behaved in the same way as the wild-type, but the $p t a / d s p A$ double mutant retained a significant proportion of its photosynthetic complexes, in particular the chlorophyll-protein complexes. Therefore the $p t a / d s p A$ double mutant is clearly deficient in a signalling pathway required to initiate degradation of these complexes under these conditions. Again, we suggest that this pathway involves gene expression controlled by one or more response regulators whose phosphorylation level is determined by phosphotransfer from both DspA and acetyl phosphate (Figure 4). In this case the double mutation is needed to produce a detectable phenotypic effect, suggesting that either DspA or acetyl phosphate alone are sufficient to maintain high enough levels of phosphorylation of the relevant response regulator(s) (Figure 4). The fact that the phenotypic difference is seen only in the double mutant very strongly suggests that DspA and acetyl phosphate are acting as phosphodonors to the same response regulator(s). Again, it appears that a high level of response regulator phosphorylation promotes the degradation of the photosynthetic complexes.

\section{Acetyl phosphate as a potential global regulator of gene expression in Synechocystis 6803}

In $E$. coli the concentration of acetyl phosphate has been shown to be dependent on the metabolic state of the cell as well as the growth phase, carbon source, $\mathrm{pH}$ and temperature $[8,31,32]$, therefore acetyl phosphate could potentially serve as a global sensor of the physiological state of the cell in E. coli. Acetyl phosphate is known to phosphorylate several RR's, including CheY, $\mathrm{NR}_{\mathrm{I}}, \mathrm{PhoB}$ and OmpR [8]in vivo, but its ability to phosphorylate response regulators in vivo depends on the $K_{m}$ of the response regulator for acetyl phosphate, which in many cases is too high to allow phosphorylation [33]. In the four systems studied in one investigation of crosstalk between two component systems, one, the Uhp system was shown to be activated by acetyl phosphate when $E$. coli is grown on pyruvate [34]. There have been no comparable studies in cyanobacteria, but it seems likely that the level of acetyl phosphate would change in response to physiological stress, in particular nutrient deprivation. If this is the case, it seems likely that the $K_{m}$ of at least some response regulators could be tuned to the physiological concentrations of acetyl phosphate in Synechocystis 6803, allowing the level of acetyl phosphate to be part of the signalling process. The level of pigment complexes in the pta mutant was close to normal in nutrient replete conditions (table 2), indicating that the level of acetyl phosphate is not having an effect on overall expression of photosynthetic gene expression via a number of response regulators, but we cannot rule out that the cumulative effect of 
$p t a^{-}$and $d s p A^{-}$that we observe in nutrient depleted conditions may be influenced by a reduced phosphorylation of response regulator(s) other than those phosphorylated by DspA.

\section{Role of DspA in initiating degradation of photosynthetic complexes during nutrient stress in Synechocystis 6803}

NblS (DspA homologue) was originally identified in Synechococcus 7942 as a factor important for initiating the degradation of the photosynthetic complexes (in particular the phycobilisomes) during nitrogen starvation [21]. In Synechocystis 6803 there is strong evidence for DspA as a global regulator controlling the expression of many genes involved in photosynthesis, carbon metabolism and stress responses [15,17-19,21,22]. However, dspA mutations in Synechocystis 6803 have not previously been shown to induce a non-bleaching phenotype like that seen in Synechococcus 7942. Here we have shown that such a phenotype can be seen in the $d s p A$ mutant of Synechocystis 6803, provided that the pta gene is also deleted. The phenotype is still not identical to that seen in Synechococcus 7942, however, since in Synechocystis 6803 it is not only the degradation of the phycobilisomes which is affected but also the degradation of chlorophyll-protein complexes (Table 2).

\section{Conclusion}

It is clear that, under our conditions, DspA is a sensor for nitrogen starvation in association with the level of acetyl phosphate, leading to photosystem degradation, since this response occurs similarly in the wild-type and in the $d s p A$ single mutant (Table 2). However, it is unlikely to be coincidental that non-bleaching phenotypes are associated with nblS/dspA mutations both in Synechococcus 7942 and in Synechocystis 6803. We suggest that there must be other, as yet undetermined, conditions in which acetyl phosphate levels in wild-type cells are low. Under such conditions, DspA activity will become a physiologically important factor controlling the degradation of the photosynthetic complexes. The presence of Pta in Synechocystis 6803 may reflect its more flexible metabolic lifestyle compared to other cyanobacteria.

\section{Methods}

\section{Strain and culture conditions}

All strains used are derivatives of the glucose-tolerant strain of Synechocystis 6803 [35] and are listed in Table 1. All strains were grown in BG-11 medium [36] supplemented with $10 \mathrm{mM}$ sodium bicarbonate and $12 \mathrm{mM}$ sodium thiosulphate at $30^{\circ} \mathrm{C}$ in an illuminated shaking incubator (New Brunswick) under white light. For nutrient deprivation studies, BG-11 medium lacking $\mathrm{NaNO}_{3}$ but supplemented with $5 \mathrm{mM}$ glucose was used, this also served as the wash medium. Illumination was at $80 \mu \mathrm{Em}^{-}$ ${ }^{2} \mathrm{~s}^{-1}$ unless otherwise indicated. Cultures for nitrogen star- vation experiments were grown in BG-11 with glucose at a low cell density for at least 3 days prior to nitrogen starvation. Erythromycin and kanamycin were added to media or plates when required at a final concentration 50 $\mu \mathrm{g} \mathrm{ml-1}$.

\section{Sequence analysis}

Deduced amino acid sequences were obtained form Cyanobase [37], the National Centre for Biotechnology Information (NCBI) [38] and the DOE Joint Genome Institute [39]. Protein to protein BLASTP 2.2.6/3 searches were performed at NCBI and Cyanobase websites. Protein sequences were analysed by Pfam $[40,41]$, SMART [23,42] and Interpro [43]. CLUSTALW alignments [44] were performed at the European Bioinformatics Institute [45].

\section{Molecular biology}

Routine DNA manipulations were performed as in [46] using reagents purchased from QIAGEN, New England Biolabs, Inc., Promega and Sigma. Genomic DNA from Synechocystis 6803 was prepared as described by Porter [47]. The primers used for PCR amplification of the $d s p A$ gene had the sequences 5 '-gcgagctcttctgtgtccaatccaacg and 5 '-gcggtaccatggattgatacacggccag. The same primers were used to monitor segregation in the transformant. The primers used for PCR amplification of the pta gene had the sequences 5'-GCGAGCTCCCTTTATTTAAGCACCACC and 5'-GCGGTACCTTGCAAAGCTGTAATTACCACC and were also used to monitor segregation in the transformants. Primers were purchased from Invitrogen Technologies.

\section{Construction of dspA and pta mutants of Synechocystis 6803}

The pta open reading frame (slr2132 in the Cyanobase database) and the $d s p A$ open reading frame (sll0698) were amplified by PCR from Synechocystis 6803 DNA, using primers shown above. The PCR products were cloned into pBluescriptII KS +. The slr2132 sequence was cut at a PstI site at position 872 in the coding sequence, and an erythromycin resistance cassette (pBSEmEco1) was ligated in. The sll0698 sequence was cut at an EcoRI site at position 1384 in the coding sequence, and a kanamycin resistance cassette (pUC4K) was ligated in [48,49]. Slr2132 is 265 bp downstream of slr1888 and it is probably transcribed on an mRNA encoding only Pta, so its interruption should not have any polar effects. Sll0698 is upstream of two putative transposases sll0699 and sll0700. The glucosetolerant strain of Synechocystis 6803 was transformed with the slr2132::Em ${ }^{\mathrm{R}}$ construct as described by Porter [47]. After several rounds of growth on erythromycin plates, PCR was used to check the insertion. This confirmed that the wild-type slr2132 locus had been completely replaced by the slr2132::Em ${ }^{\mathrm{R}}$ locus, and hence that the pta gene had been completely inactivated generating a fully-segregated 
pta mutant. A similar procedure was followed with the sll0698:: $\mathrm{Km}^{\mathrm{R}}$ construct, which was used to transform both the wild-type and the pta mutant, to generate a sll0698 single insertional mutant $(d s p A)$ and a sll0698:slr2132 double insertional mutant ( $p t a / d s p A)$. These mutants were shown to have segregated after six rounds of streaking to single colonies on kanamycin (plus erythromycin for $p t a$ double mutants) plates as has been observed by Hsiao et al. [22], though without glucose in this work.

\section{Procedure for initiating nutrient deprivation}

$50 \mathrm{ml}$ cultures were grown to mid-log phase in BG11 medium. Each culture was then harvested by centrifugation, resuspended in $30 \mathrm{ml}$ of wash medium, harvested a second time and resuspended in $10 \mathrm{ml}$ of BG11 medium supplemented with glucose but lacking $\mathrm{NaNO}_{3}$. This was then divided into two $5 \mathrm{ml}$ portions, which were then used to inoculate parallel $20 \mathrm{ml}$ cultures.

\section{Pigment content analysis}

Fluorescence emission spectra were measured at $77 \mathrm{~K}$ in a Perkin-Elmer LS50 luminescence spectrometer equipped with a liquid-nitrogen sample holder. Cells were harvested by centrifugation and resuspended in growth medium to a chlorophyll $a$ concentration of $5 \mu \mathrm{M}$ [28]. Re-absorption of emitted fluorescence was negligible at the cell concentrations used. The samples were not mixed with glycerol, as this alters the low temperature fluorescence emission spectrum [29]. The samples were then injected into silica tubes ( $2 \mathrm{~mm}$ internal diameter) and dark adapted for 5 minutes. Samples were rapidly frozen by immersion in liquid nitrogen. Excitation and emission slit widths were $5 \mathrm{~nm}$. Chlorophyll $a$ was excited at 435 $\mathrm{nm}$ : light at this wavelength is not significantly absorbed by the phycobilisomes [50]. Chlorophyll $a$ concentration was estimated from the absorption of methanol extracts at $665 \mathrm{~nm}$ [51]. Spectra from different samples were normalised to the PSI peak (emission at $725 \mathrm{~nm}$ ). Cell absorption spectra were recorded with an Aminco DW2000 spectrophotometer. The concentrations of chlorophyll and phycocyanin were estimated from the spectra using the equations of Myers et al. [27]. Cell numbers were estimated from the optical density at $750 \mathrm{~nm}$, calibrated using a hemocytometer.

\section{Abbreviations}

aa - amino acids; Dsp - drug sensory protein, HAMP histidine kinases, adenyl cyclases, methyl binding proteins and phosphatases; NblS - non-bleaching mutant

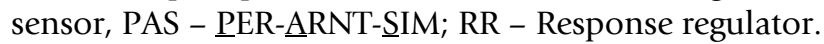

\section{Authors' contributions}

SSM performed the spectroscopy, analysed the segregation of the mutants and drafted the manuscript. CWM supervised SSM at UCL and drafted the manuscript. MKA conceived the study, constructed the interposon mutants and drafted the manuscript.

\section{Additional material}

\section{Additional File 1}

ClustalW alignment of NblS (DspA, Ycf26) putative amino acid sequences.

Click here for file

[http://www.biomedcentral.com/content/supplementary/1471-

2180-5-47-S1.doc]

\section{Acknowledgements}

SSM is supported by a studentship from the Office of Graduate Studies and Research, University of the West Indies. This work was funded by a New Initiative Grant to MKA from the Office of Planning and Institutional Research, University of the West Indies. CWM acknowledges financial support from the Biotechnology and Biological Sciences Research Council.

\section{References}

I. Niyogi KK: Photoprotection Revised: Genetic and molecular approaches. Annu Rev Plant Physiol Plant Mol Biol 1999, 50:333-359.

2. Parkinson JS, Kofoid EC: Communication modules in bacterial signaling proteins. Annu Rev Genet 1992, 26:71-II2.

3. Parkinson JS: Signal transduction schemes of bacteria. Cell 1993, 73:857-87I.

4. Stock AM, Robinson VL, Goudreau PN: Two-Component Signal Transduction. Annu Rev Biochem 2000, 69:183-215.

5. Robinson VL, Buckler DR, Stock AM: A tale of two components: a novel kinase and a regulatory switch. Nature Struct Biol 2000, 7:626-633.

6. Feng J, Atkinson MR, McCleary W, Stock JB, Wanner BL, Ninfa AJ: Role of phosphorylated metabolic intermediates in the regulation of glutamine synthetase synthesis in Escherichia coli. J Bacteriol | 992, |74:606|-6070.

7. McCleary WR, Stock JB, Ninfa AJ: Is acetyl phosphate a global signal in Escherichia coli? J Bacteriol 1993, I 75:2793-2798.

8. McCleary WR, Stock JB: Acetyl phosphate and the activation of two-component response regulators. J Biol Chem 1994, 269:31567-31572.

9. Wolfe AJ: The Acetate Switch. Microbiol Mol Biol Rev 2005, 69:12-50.

10. Brown TDK, Jones-Mortimer MC, Kornberg HI: The enzymatic interconversion of acetate and acetyl-coenzyme $A$ in Escherichia coli. J Gen Microbiol 1977, 102:327-336.

II. Chamnongpol S, Groisman EA: Acetyl Phosphate-dependent Activation of a Mutant PhoP Response Regulator that Functions Independently of its Cognate Sensor Kinase. J Mol Biol 2000, 300:29|-305.

12. Appleman JA, Stewart V: Mutational analysis of a conserved signal-transduction element: the HAMP linker of the Escherichia coli nitrate sensor NarX. J Bacteriol 2003, 185:89-97.

13. Gilles-Gonzales MA, Gonzales G: Signal transduction by hemecontaining PAS-domain proteins. J Appl Physiol 2004, 96:774-783.

14. Ashby MK, Houmard J, Mullineaux CW: The ycf27 genes from cyanobacteria and eukaryotic algae: distribution and implications for chloroplast evolution. FEMS Microbiol Lett 2002, 2। 4:25-30.

15. Suzuki I, Los DA, Kanesaki Y, Mikami K, Murata N: The pathway for perception and transduction of low-temperature signals in Synechocystis. EMBO J 2000, 19:1327-1334.

16. Bartsevich VV, Shestakov SV: The dspA gene product of the cyanobacterium Synechocystis sp. strain PCC 6803 influences sensitivity to chemically different growth inhibitors and has amino acid similarity to histidine protein kinases. Microbiology 1995, 141:2915-2920. 
I7. Suzuki I, Kanesaki Y, Mikami K, Kanehisa M, Murata N: Cold-regulated genes under the control of the cold sensor Hik33 in Synechocystis. Mol Microbiol 200I, 40:235-244.

8. Marin K, Suzuki I, Yamaguchi K, Ribbeck K, Yamamoto H, Kanesaki Y, Hagemann M, Murata N: Identification of histidine kinases that act as sensors in the perception of salt stress in Synechocystis sp. PCC 6803. Proc Natl Acad Sci USA 2003, I 00:906 I-9066.

19. Tu C, Shrager J, Burnap RL, Postier BL, Grossman AR: Consequences of a deletion in dsp $A$ on transcript accumulation in Synechocystis sp. strain PCC 6803. J Bacteriol 2004, I 86:3889-3902.

20. Paithoonrangsarid K, Shoumskaya MA, Kanesaki Y, Satoh S, Tabata S Los DA, Zinchenko VV, Hayashi H, Tanticharoen M, Suzuki I, Murata $\mathrm{N}$ : Five histidine kinases perceive osmotic stress and regulate distinct sets of genes in Synechocystis. I Biol Chem 2004 279:53078-53086

21. van Waasbergen LG, Dolganov N, Grossman AR: nbIS, a gene involved in controlling photosynthesis-related gene expression during high light and nutrient stress in Synechococcus elongatus PCC 7942. I Bacteriol 2002, I 84:248I-2490.

22. Hsiao H, He Q, van Waasbergen LG, Grossman AR: Control of photosynthetic and high-light responsive genes by the histidine kinase DspA: negative and positive regulation and interactions between signal transduction pathways. J Bacteriol 2004 , I 86:3882-3888.

23. Letunic I, Goodstadt L, Dickens NJ, Doerks T, Schultz J, Mott R, Cic carelli F, Copley RR, Ponting CP, Bork P: Recent improvements to the SMART domain-based sequence annotation resource. Nucleic Acids Res 2002, 30:242-244.

24. Prodom [http://prodes.toulouse.inra.fr/prodom/current/html/ home.php]

25. Zhu $Y$, Inouye $M$ : The HAMP Linker in Histidine Kinase Dimeric Receptors is Critical for Symmetric Transmembrane Signal Transduction. J Biol Chem 2004, 279:48I52-48I 58 .

26. Kristich CJ, Ordal GW: Analysis of Chimeric Chemoreceptors in Bacillus subtilis Reveals a Role for CheD in the Function of the McpC HAMP Domain. I Bacteriol 2004, I 86:5950-5955.

27. Myers J, Graham JR, Wang RT: Light harvesting in Anacystis nidulans studied in pigment mutants. Plant Physiol 1980 66: I| $44-1 \mid 49$.

28. Mullineaux CW: Excitation energy transfer from phycobilisomes to Photosystem I in a cyanobacterial mutant lacking Photosystem II. Biochim Biophys Acta 1994, I I 84:7 I-77.

29. Mao H, Li G, Li D, Wu Q, Gong Y, Zhang X, Zhao N: Effects of glycerol and high temperatures on the structure and function of phycobilisomes in Synechocystis sp. PCC 6803. FEBS Lett 2003, 553:68-72

30. Rocap G, Larimer FW, Lamerdin J, Malfatti S, Chain P, Ahlgren NA, Arellano A, Coleman M, Hauser L, Hess WR, Johnson ZI, Land M, Lindell D, Post AF, Regala W, Shah M, Shaw SL, Steglich C, Sullivan MB, Ting CS, Tolonen A, Webb EA, Zinser ER, Chisholm SW: Genome divergence in two Prochlorococcus ecotypes reflects oceanic niche differentiation. Nature 2003, 424:1042-1047.

31. Heyde M, Laloi P, Portalier R: Involvement of carbon source and acetyl phosphate in the external-PH-dependant expression of porin genes in Escherichia coli. I Bacteriol 2000, I 82:198-202.

32. Pruss BM, Wolfe AJ: Regulation of acetyl phosphate synthesis and degradation, and the control of flagellar expression in Escherichia coli. Mol Microbiol 1994, I 2:973-984.

33. McCleary WR: The activation of PhoB by acetylphosphate. Mol Microbiol 1996, 20: I I55-I I63.

34. Verhamme DT, Arents JC, Postma PW, Crielaard W, Hellingwerf K Investigation of in vivo cross-talk between key two-component systems of Escherichia coli. Microbiology 2002, I 48:69-78.

35. Williams JGK: Construction of specific mutations in Photosystem II photosynthetic reaction center by genetic engineering methods in Synechocystis 6803. In Methods in Enzymology Volume 167. Edited by: Packer, L, Glazer AN. San Diego: Academic Press; 1988:766-778.

36. Castenholz RW: Culturing methods for cyanobacteria. In Methods in Enzymology Volume 167. Edited by: Packer L, Glazer AN. San Diego: Academic Press; 1988:68-93.

37. Cyanobase [http://www.kazusa.or.jp/cyano/]

38. National Centre for Biotechnology Information [http:// www.ncbi.nlm.nih.gov/]
39. DOE Joint Genome Institute [http://genome.jgi-psf.org/ mic home.html]

40. Protein families database of alignments and HMMs [http:// www.sanger.ac.uk/Software/Pfam/

41. Bateman A, Birney E, Cerruti L, Durbin R, Etwiller L, Eddy SR, Griffiths-Jones S, Howe KL, Marshall M. Sonnhammer EL: The Pfam protein families database. Nucleic Acids Res 2002, 30:276-280.

42. Simple Modular Architecture Research Tool [http://
[ smart.embl-heidelberg.de/]

43. Interpro TMHMM Server [http://www.cbs.dtu.dk/services/ $\mathrm{TMHMM} /]$

44. Thompson JD, Higgins DG, Gibson TJ: CLUSTALW: improving the sensitivity of progressive multiple sequence alignment through sequence weighting, position-specific gap penalties and weight matrix choice. Nucleic Acids Res 1994, 22:4673-4680.

45. European Bioinformatics Institute [http://www.ebi.ac.uk/clus talw/]

46. Sambrook J, Fritsch EF, Maniatis T: Molecular cloning: a laboratory manual. Second edition. Cold Spring Harbor Laboratory Press, Cold Spring Harbor, NY; 1989.

47. Porter RD: DNA Transformation. In Methods in Enzymology Volume 167. Edited by: Packer L, Glazer AN. San Diego: Academic Press; 1988:703-712

48. Ashby MK, Mullineaux CW: Cyanobacterial ycf $\mathbf{2 7}$ gene products regulate energy transfer from phycobilisomes to photosystems I and II. FEMS Microbiol Lett 1999, I 8 I:253-260.

49. Ashby MK, Mullineaux CW: The role of ApcD and ApcF in energy transfer from phycobilisomes to PS I and PS II in a cyanobacterium. Photosynth Res 1999, 61:169-179.

50. Li Y, Zhang J, Xie J, Zhao J, Jiang L: Temperature-induced decoupling of phycobilisomes from reaction centers. Biochim Biophys Acta 200I, I 504:229-234.

5I. Porra RJ, Thompson WA, Kriedemann PE: Determination of accurate excitation coefficients and simultaneous equations for assaying chlororphylls $a$ and $b$ extracted with four different solvents: Verification of the concentration of chlorophyll standards by atomic absorption spectroscopy. Biochim Biophys Acta 1989, 975:384-394.
Publish with Bio Med Central and every scientist can read your work free of charge

"BioMed Central will be the most significant development for disseminating the results of biomedical research in our lifetime. "

Sir Paul Nurse, Cancer Research UK

Your research papers will be:

- available free of charge to the entire biomedical community

- peer reviewed and published immediately upon acceptance

- cited in PubMed and archived on PubMed Central

- yours - you keep the copyright

Submit your manuscript here:

http://www.biomedcentral.com/info/publishing_adv.as
BioMedcentral 